Original article

\title{
Epidemiology of hospital-based COVID- 19 cluster in a tertiary care cancer hospital, Chennai, India 2020
}

\author{
Suganya Barani ${ }^{\text {a, }}$, Nuzrath Jahan ${ }^{\text {a, }}$, Mathan Karuppiah ${ }^{\text {a, }}$, Sirshendu Chaudhuri $^{\text {a }}$, \\ Mohankumar Raju ${ }^{a}$, Manickam Ponnaiah ${ }^{a, *}$, Swaminathan Rajaraman ${ }^{\text {c }}$, \\ Venktesh Vaidhyalingam ${ }^{c}$, Parasuraman Ganeshkumar ${ }^{\mathrm{a}}$, Girish Kumar CP ${ }^{\mathrm{a}}$, \\ Sendhilkumar Muthappan ${ }^{\mathrm{a}}$, Jegadeesan Murugesan ${ }^{\mathrm{b}}$, Mahalakshmi Srinivasan ${ }^{\mathrm{b}}$, \\ Usha Krishnan $^{\mathrm{b}}$, Alby John Varghese ${ }^{\mathrm{b}}$ \\ ${ }^{a}$ Hospital Cluster Investigation Team: ICMR-National Institute of Epidemiology, Chennai, India \\ ${ }^{\mathrm{b}}$ Greater Chennai City Corporation, Chennai, India \\ ${ }^{\mathrm{c}}$ Cancer Institute (WIA), Chennai, India
}

\section{A R T I C L E I N F O}

\section{Keywords:}

COVID-19

SARS-CoV-2

Disease outbreaks

Hospital cluster

\begin{abstract}
A B S T R A C T
Objectives: To identify risk factors associated with Coronavirus disease 2019 (COVID-19) in a Tertiary care cancer hospital-based cluster and recommend control measures.

Methods: We conducted tracing and confirmation among hospital and community contacts. We telephonically interviewed and abstracted information from hospital records and registers. We described the cluster by time, place and person. We conducted unmatched case-control study to compare risk factors and computed Odds Ratio (OR) and 95\% confidence interval.

Results: We confirmed COVID-19 in 21 of 1478 tested (1.4\%). Secondary attack (\%) of COVID-19 among 824 contacts was higher among in-patients of block A (18), household contacts (3.4), housekeeping staff (3.3) and nurses (1.7). The cluster started on April 22 with two successive peaks five days apart and lasted until May 8. Being male, patients aged $>33$ years $[\mathrm{OR}=30 \cdot 7 ; 95 \% \mathrm{CI}=3.6$ to 264 ], having hypertension $[\mathrm{OR}=4 \cdot 3$; $95 \% \mathrm{CI}$ $=1 \cdot 1$ to $16 \cdot 7$ ] or diabetes $[\mathrm{OR}=3 \cdot 8 ; 95 \% \mathrm{CI}=1 \cdot 0$ to $14 \cdot 1]$ were associated with COVID-19. Mask compliance was poor (20\%) among hospital workers.

Discussion: We recommended screening of all patients for diabetes and hypertension and isolation/testing of anyone with influenza-like illness for preventing COVID-19 clusters in hospital settings.
\end{abstract}

\section{Introduction}

The ongoing pandemic of Coronavirus disease 2019 (COVID-19) caused by Severe Acute Respiratory Syndrome- Coronavirus 2 (SARSCoV-2) infection is widespread. The epidemiology of COVID-19 is characterised through systematically collected data from surveillance systems. At the same time, investigation of COVID-19 super-spreader events reported from various locations ${ }^{1,2}$ and that of clusters from settings such as restaurant, ${ }^{3}$ cruise ship, ${ }^{4,5}$ social gatherings ${ }^{6,7}$ have contributed significantly to understand dimensions of COVID-19 epidemiology.

In the Indian context, several such spreader events ${ }^{8}$ and clusters ${ }^{9}$ were reported across a variety of settings. However, among these clusters, hospital-based clusters are critical and potentially could provide information about transmission pathways between patients and the health care workers. ${ }^{10}$ Due to the unavoidable proximity within the hospital settings, patients could spread the infection among fellow patients and the healthcare professionals with the extreme consequence of shutting down of the hospital services. ${ }^{11}$ Besides closure, various control measures have to be carried out that include partial closure of contaminated areas, isolation of infected patients and contacts, surveillance and testing of patients and staff, infection control measures like enforced hand hygiene, reprocessing and sterilisation of devices. ${ }^{12}$ Additionally, hospital clusters carry the risk of spilling over to the

\footnotetext{
* Corresponding author. ICMR-National Institute of Epidemiology, R127, TNHB, Ayappakkam, Chennai, Tamil Nadu, 600 077, India.

E-mail address: manickam@nie.gov.in (M. Ponnaiah).

1 equal first authors.
} 
community as well. $^{13}$ Prompt and systematic investigation of hospital-based COVID-19 clusters could provide clues to circumstances of transmission and, therefore, advise on prevention and control measures. $^{14}$

On $28^{\text {th }}$ April 2020, a cluster of 10 persons who were tested positive for COVID-19 in a Chennai-based cancer care hospital namely "Cancer Institute (WIA), Adyar, Chennai (henceforth referred as Tertiary care cancer hospital) was reported by the Tamil Nadu State public health system, South India. We systematically investigated this cluster using WHO guidelines. ${ }^{14}$ The objectives of the investigation were to (1) describe epidemiological and clinical characteristics of index case-patient and initial case-patients (2) describe nature, type and characteristics of contacts of the case-patients (3) characterise cases by time, place and person (4) identify factors associated with COVID-19 for this cluster.

\section{Methods}

\subsection{Study setting}

The study was conducted in Cancer Institute (WIA), Chennai, India is a tertiary-level cancer care facility which has two campuses namely "Campus One" and "Campus two". "Campus one" includes inpatient blocks (A \& B), Radiotherapy and Diagnostic blocks whereas "Campus two" includes a residential block, imaging facility and day-care wards.

\subsection{Descriptive epidemiology of index and initial case-patients}

We defined a case-patient as a person, either a hospital worker or an inpatient in a Tertiary care cancer hospital, with laboratory-confirmed COVID-19 between April 13 and May 3, 2020, irrespective of clinical symptoms or signs. We defined an index case-patient as a person, either a hospital worker or an inpatient in the Tertiary care cancer hospital with laboratory-confirmed SARS-CoV-2 infection, between April 13 and May 3, 2020, irrespective of clinical symptoms or signs and who had no epi-linkage with other case-patients. Initial case-patients were the COVID-19 positive persons detected before the commencement of investigation on April 28.

Using the definitions above, we collected information on the movements of the initial case patients and all case-patients within the hospital through a combination of telephone interviews, the abstraction of patient's clinical records, review of registers and key informant interviews of ward in-charge/supervisor, staff nurses/technologists/doctors in duty for movements inside specific block A (wherein the index-case patient was identified) and that of the Tertiary care cancer hospital. For each case patient, we collected information on age, gender, residence, date of detection of COVID-19 and clinical characteristics. We described the socio-demographic, clinical and comorbidity status. We mapped the movements of all case-patients and that of the location of health care workers involved during the reference period of exposure.

\subsection{Nature, type and characteristics of contacts of the case-patients}

We defined two types of contacts, hospital and community contacts. Hospital contact is a person who came in contact with case-patients during the period of exposure anywhere inside the hospital. We defined community contact as a person who came in contact with the case-patients between April 13 and May 3, 2020, outside the hospital.

We categorised contacts as healthcare worker contacts (doctors, nurses, para-clinical, housekeepers) and non-healthcare workers (patients, non-clinical staff, patients' bystander, and community contacts). We categorised them as hospital and community contacts after compilation from the various sources such as hospital administration records for staff, ward registers and the official records of the local governing body for enlisted contacts as part of their community contact tracing protocol. In addition to the basic demographic characteristics, we collected data on the testing status and offered testing for all the identified contacts. We described the characteristics of contacts by category and test positive status. We calculated the secondary attack rate among contacts of case-patients based on the number of contacts identified for each type of case-patient.

\subsection{Descriptive epidemiology of cases}

We created a line-list for all case-patients with their exposure, category, comorbidity, and clinical characteristics. We calculated the attack rate by age and gender by using appropriate hospital or community contacts or those tested as denominators. We drew an epidemic curve based on the date of laboratory confirmation. We prepared a spot map to identify the distribution of cases by location and type of contacts within the hospital. We used descriptive epidemiological information and interviews with key informants and generated hypotheses.

\subsection{Unmatched case-control study}

We designed an unmatched case-control study to test the hypothesis that transmission dynamics within the hospital setting favoured patients belonging to higher age group contracting COVID-19. We considered all COVID-19 positive individuals and their contacts in hospital and in the community as the study population. We needed 18 cases and 72 controls for the assumptions of odds ratio (OR) of 4.5 for older age as risk factor for COVID-19, 30\% exposure among controls, power of $80 \%$, $95 \%$ Confidence Interval (CI) and 1:4 ratio of cases to controls.

We defined cases as individuals tested positive for COVID-19 and controls as contacts (hospital and community) tested negative for COVID-19. We selected all the 21 confirmed cases for our study. We created a line-list of controls by health care workers (doctors, nurses, para-clinical, and housekeepers) and non-healthcare (patients, nonclinical staff, patients' bystander, and community contacts) categories. We created a line-list of all the contacts by interviewing the hospital authority, the case patients and reviewing the various hospital records such as patient case sheets and staff duty registers and selected the controls from this line list. We created a pre-tested questionnaire in an open data kit (ODK) to collect information on socio-demographic characteristics and exposure history related to travel, contact, and comorbidities. We asked specific questions on aerosol-generating procedures and the use of personal protective equipment from health care workers. We collected the data through telephonic interviews after obtaining consent.

We calculated descriptive statistics [mean, median, Interquartile range (IQR)] for continuous variables. We calculated proportions for categorical variables and tested them using chi-square. We used the median age of controls to dichotomise the age of cases. We used logistic regression to calculate crude and adjusted ORs with 95\% CI. We examined for confounders and effect modifiers by stratified analysis. We constructed directed acyclic graphs (DAGs) to identify potential confounders. We compared the -2 log-likelihood ratios of models without and without potential confounders. We checked for effect measure modification by comparing models with and without interaction terms for effect modifiers. We used Epi Info version 7·2·3.1 for analysis.

\subsection{Laboratory confirmation}

We confirmed the COVID-19 cases through RT-PCR done in the Indian Council of Medical Research (ICMR) approved ${ }^{15}$ COVID-19 testing laboratories of the State Public Health Directorate and at the ICMR-NIE.

\subsection{Human participant protection}

The study protocol was approved by the institutional human ethics committee of Cancer Institute (WIA), Chennai, India. Informed verbal consent was obtained from the participants before commencing the 
telephone interview.

Role of the funding source

The investigation was internally funded by ICMR and did not receive any specific grant funding from agencies in the public, commercial, or not-for-profit sectors. The funder of the study was involved in reviewing the study design, writing of the manuscript, and the decision to submit the paper for publication. All authors had access to all the data in the study and had final responsibility for the decision to submit for publication.

\section{Results}

\subsection{Epidemiological and clinical characteristics of index case-patient and initial case-patients}

The index case-patient P1 had lung carcinoma and was admitted to Block A of hospital on April 14. He was tested positive for COVID-19 on April 22 after he complained of fever and respiratory distress from April 16. He had a history of exposure to healthcare workers of another referral hospital who tested positive for COVID-19 during the same reference period.

We identified 10 initial case-patients and seven of them were patients admitted in block $\mathrm{A}$ and remaining three were health care workers. Among the healthcare workers, two were working in Block A while the other person was working in the radiotherapy unit and came in contact with one of the initial case-patient during a diagnostic procedure. The median age of initial case-patients was 40 years (IQR: 28-57), and eight were men. All hospitalised initial case-patients were cancer patients admitted in block A for management of their primary condition and other comorbid conditions (Table 1).

\subsection{Nature, type and characteristics of contacts of the case-patients}

We could identify a total of 1478 contacts. Among the hospital contacts, the majority, almost one third were $(n=420,28 \%)$ nonclinical health care workers and an almost equal number of paraclinical workers $(\mathrm{n}=339 ; 23 \%)$ and nurses $(\mathrm{n}=331,22 \%)$ followed by doctors $(\mathrm{n}=195 ; 13 \%)$, housekeeping staff $(\mathrm{n}=120 ; 8 \%)$ and patients $(n=75 ; 5 \%)$. Besides, we could identify 59 community contacts. We could do RT-PCR for the 824 (56\%) of the total 1478 contacts identified. The median age of the contacts was 33 years (IQR 23-44 years) with a female preponderance $(n=983,67 \%)$. We could test all the 75 patient contacts. Of the remaining tested, 91\% $(n=749)$ were hospital staff.

Among the hospital staff, we could test $36 \%(n=331)$ of nurses, $49 \%$ $(\mathrm{n}=165)$ of allied clinical staff and $61 \%(\mathrm{n}=195)$ of doctors and $75 \%$ $(n=120)$ of housekeepers and $61 \%(n=257)$ of non-clinical staff.

\subsection{Descriptive epidemiology of cases}

In the Tertiary-level cancer care hospital, we identified 21 COVID-19 cases from April 21 to May 8, with an overall attack rate of $2.5 \%$ (Table 2). The majority of the cases $(n=19)$ cases were either patients or healthcare workers, whereas two cases were from community contacts. Four of 13 patients had symptoms of fever $(n=2)$, respiratory distress $(\mathrm{n}=1)$, runny nose $(\mathrm{n}=1)$ and loose stools $(\mathrm{n}=1)$ and others were asymptomatic.

The attack rate was higher among males $(\mathrm{n}=11,3.6 \%)$, aged $<20$ years $(50 \%)$, and elderly $>60$ years $(19 \%)$ (Table 2$)$. The secondary attack was highest among the inpatients (15\%) followed by community/ household contacts (3.1\%). Secondary attack was higher (15.5\%) among the patients of block A. Among health care workers, it was highest among housekeeping staff $(3 \cdot 3 \%)$ and nurses (1.7\%) (Table 3$)$. The overall case-fatality was $5 \%(n=1)$.

In terms of the distribution of the cases by date of confirmation (Fig. 1), the initial half of the cases were from block $\mathrm{A}$, and the latter part

Table 1

Descriptive characteristics of COVID-19 case-patients of hospital-based cluster in a Tertiary care cancer hospital, Chennai, South India, 2020.

\begin{tabular}{|c|c|c|c|c|c|c|c|}
\hline Case ID & Age & Gender & Type of case patient & Place of stay (In-patient \& patient) & Duration of stay (in days) & Primary diagnosis (If any) & Comorbidity \\
\hline P1 & 46 & M & Inpatient & Block A & 11 & Lung cancer & $\begin{array}{l}\text { Urinary tract } \\
\text { infection, anaemia, } \\
\text { leukopenia }\end{array}$ \\
\hline P2 & 67 & M & Inpatient & Block A & 4 & Oropharyngeal cancer & Anaemia \\
\hline P3 & 65 & M & Inpatient & Block A & 12 & Lymphoma & $\begin{array}{l}\text { DM, UTI, hiatus } \\
\text { hernia, electrolyte } \\
\text { imbalance }\end{array}$ \\
\hline P4 & 52 & M & Out/inpatient & Block A & 6 & Pancreatic carcinoma & $\begin{array}{l}\text { Hypertension, } \\
\text { Diabetes, } \\
\text { Hypothyroidism }\end{array}$ \\
\hline P5 & 55 & M & Inpatient & Block A & 3 & Lung cancer & Diabetes \\
\hline P6 & 68 & M & Inpatient & Block A & 19 & Oropharyngeal cancer & $\begin{array}{l}\text { Diabetes, Chronic } \\
\text { Obstructive } \\
\text { Pulmonary Disease, } \\
\text { Discharging neck } \\
\text { node }\end{array}$ \\
\hline P7 & 34 & M & Inpatient & Block A & 9 & Rectal cancer & Hypertension \\
\hline P8 & 16 & M & Inpatient & Block B & 8 & Acute leukaemia & - \\
\hline P9 & 43 & M & Inpatient & Block A & 5 & Sarcoma & - \\
\hline P10 & 64 & $\mathrm{~F}$ & Inpatient & Block A & 6 & Chronic Lymphocytic Leukaemia & Diabetes \\
\hline P11 & 44 & $\mathrm{~F}$ & Out/inpatient & Block A & 5 & Breast cancer & - \\
\hline P12 & 58 & $\mathrm{~F}$ & Inpatient & Block A & 3 & Breast cancer & - \\
\hline P13 & 35 & $\mathrm{~F}$ & Inpatient & Block A & 4 & Breast cancer & Hypertension \\
\hline $\mathrm{H} 1$ & 24 & $\mathrm{~F}$ & Health care worker & Block A & Not Applicable & Not applicable & - \\
\hline $\mathrm{H} 2$ & 27 & $\mathrm{~F}$ & Health care worker & Block A & & & \\
\hline H3 & 25 & M & Health care worker & Radiotherapy unit & & & \\
\hline $\mathrm{H} 4$ & 27 & M & Health care worker & Block B & & & \\
\hline H5 & 21 & $\mathrm{~F}$ & Health care worker & Block B & & & \\
\hline H6 & 21 & $\mathrm{~F}$ & Health care worker & Block B & & & \\
\hline $\mathrm{C} 1$ & 15 & $\mathrm{~F}$ & Contact & contact of P1 & & & \\
\hline $\mathrm{C} 2$ & 37 & $\mathrm{~F}$ & Contact & contact of P1 & & & \\
\hline
\end{tabular}


Table 2

Attack rate of COVID-19 by age and gender in hospital-based COVID-19 cluster a Tertiary care cancer hospital, Chennai, South India, 2020.

\begin{tabular}{|c|c|c|c|c|c|c|}
\hline \multicolumn{2}{|c|}{ Characteristics } & \multirow[t]{2}{*}{ Number of Cases } & \multicolumn{2}{|c|}{ Among all contacts } & \multicolumn{2}{|c|}{ Among contacts tested } \\
\hline & & & $\mathrm{N}$ & Attack rate per 100 persons & $\mathrm{N}$ & $(\%)$ \\
\hline \multirow[t]{4}{*}{ Age } & $\geq 20$ & 2 & 38 & $2 \cdot 6$ & 4 & 50 \\
\hline & $21-39$ & 9 & 819 & 0.9 & 393 & $2 \cdot 3$ \\
\hline & $40-59$ & 6 & 349 & 1.4 & 212 & $2 \cdot 8$ \\
\hline & $60 \&$ above & 4 & 45 & 8.9 & 19 & 21 \\
\hline \multirow[t]{2}{*}{ Gender } & Male & 11 & 495 & $3 \cdot 6$ & 305 & 3.6 \\
\hline & Female & 10 & 983 & 1.5 & 519 & 1.9 \\
\hline Overall & & 21 & 1478 & 1.4 & 824 & $2 \cdot 5$ \\
\hline
\end{tabular}

Table 3

Secondary attack rates among contacts of COVID-19 case-patients in hospitalbased COVID-19 cluster in a Tertiary care cancer hospital, Chennai, South India, 2020

\begin{tabular}{|c|c|c|c|}
\hline Categories & $\begin{array}{r}\text { Number of } \\
\text { Cases }\end{array}$ & $\begin{array}{r}\text { Total contacts } \\
\text { tested }(\mathrm{N}=824)\end{array}$ & $\begin{array}{r}\text { Secondary attack rate } \\
\text { (per } 100 \text { persons) }\end{array}$ \\
\hline Patients & 13 & 72 & 18 \\
\hline Nurses & 2 & 120 & $1 \cdot 7$ \\
\hline Housekeepers & 3 & 90 & $3 \cdot 3$ \\
\hline Doctors & 0 & 119 & 0 \\
\hline $\begin{array}{l}\text { Para clinical } \\
\text { healthcare worker }\end{array}$ & 1 & 165 & 0.6 \\
\hline $\begin{array}{l}\text { Non-clinical } \\
\text { healthcare worker }\end{array}$ & 0 & 257 & 0 \\
\hline Community contacts & 2 & 59 & $3 \cdot 4$ \\
\hline Overall & 21 & 824 & $2 \cdot 5$ \\
\hline
\end{tabular}

included cases from block A and block B. Block A was closed on April 24 when the hospital contacts of index patient P1 tested positive for COVID19. Subsequently, positive COVID-19 cases started reporting from block B. Cases from these two blocks were treated as individual clusters since there was no epidemiological linkage between patients from block A and index patient $\mathrm{P} 8$ from block B.

We could identify clustering of cases in block A and block B and identify the movements of the case-patients across the campuses for diagnostics, duty and stay. (Fig. 2a \& b). P1 had visited the imaging facility on campus two during his inpatient stay in room 16 of block A. Patient P2 went through multiple sittings of therapy as in and outpatient during the reference period. Health care worker $\mathrm{H} 3$ was a therapy technologist who attended two sittings of therapy for P2. Health care workers $\mathrm{H} 1$ and $\mathrm{H} 2$ were nurses who worked in block A from 13-19
April and stayed in the residential block on campus two. Most of the case-patients belonged to block A $(n=14)$ in terms of distribution by rooms (Fig. 2b). Two COVID-19 cases from the community contacts were linked to the index case P1. Patients of block A were mostly $(n=9)$ from that of Rooms 7, 14, and 16 (Fig. 2b). Health care workers H1 and $\mathrm{H} 2$ attended to all the patients during their working period from April 13 to 19 . There was direct contact between roommates of room numbers 16, 9 and 7 at various points in time (Fig. 2b).

\subsection{Unmatched case-control study}

We could interview 18 of the 21 cases and 113 (77\%) of 146 controls listed. Apart from one refusal from the control group, three cases and 32 controls did not attend the phone calls. The age and gender distribution of the cases and controls were similar $(\mathrm{p}=0 \cdot 3)$. We identified that being a patient $[\mathrm{OR}=5 \cdot 8 ; 95 \% \mathrm{CI}=2 \cdot 1$ to $16 \cdot 6]$ and having hypertension [OR $=4 \cdot 3 ; 95 \% \mathrm{CI}=1 \cdot 1$ to $16 \cdot 7$ ) with a history of travel within India [OR = $14 ; 95 \% \mathrm{CI}=1.2$ to 163 ] were associated with COVID-19 (Table 4). When stratified for being a patient, age more than 33 years $[\mathrm{OR}=30 \cdot 7$; $95 \% \mathrm{CI}=3.6$ to 264$]$ and male gender $[\mathrm{OR}=7 \cdot 2 ; 95 \% \mathrm{CI}=1.3$ to $39 \cdot 1$ ] were associated with cases as compared to controls (Table 5 ). We did not identify any known confounders for any of the risk factors, and therefore, we did not compute adjusted ORs. We could not identify aerosolgenerating procedures as a risk factor (Table 6).

\section{Discussion}

We investigated the COVID-19 cluster in a Tertiary care cancer hospital in Chennai, South India. We identified that the overall attack rate was higher among patients and selected subgroups of health care workers like nurses and housekeepers, and clustering was seen in two blocks of the hospital campus. As compared to controls, being a patient,

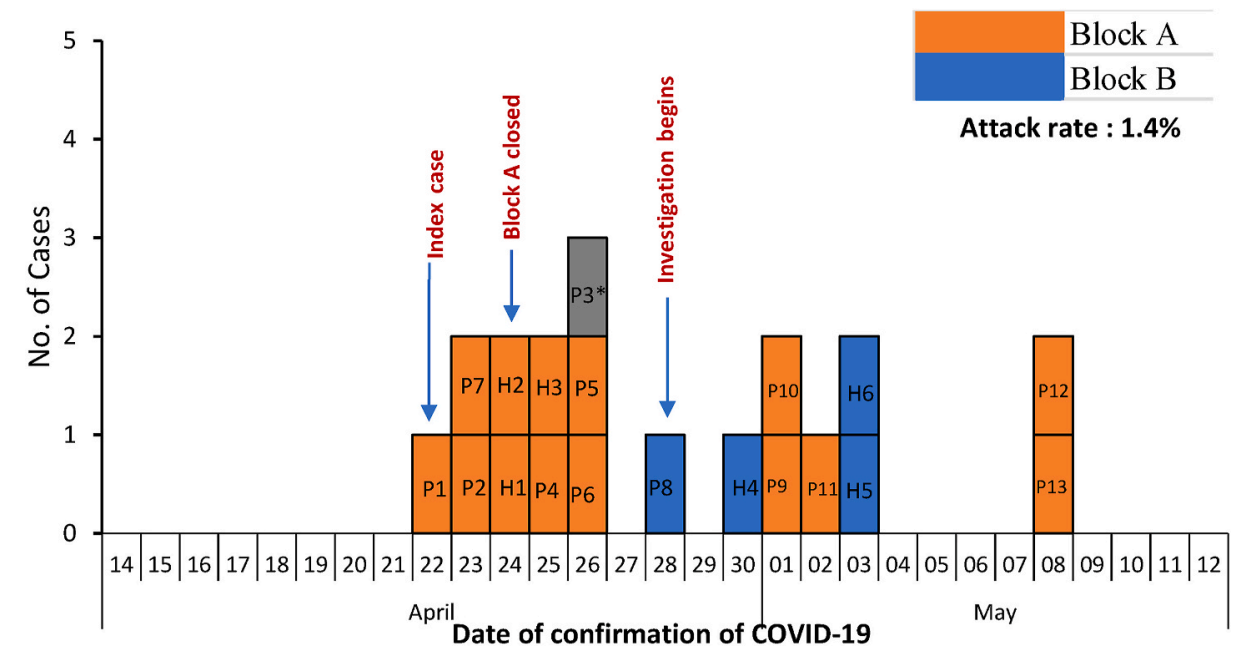

Fig. 1. Incidence of COVID-19 by date of confirmation in hospital-based cluster in a Tertiary care cancer hospital, Chennai, South India, 2020. 
Campus 2
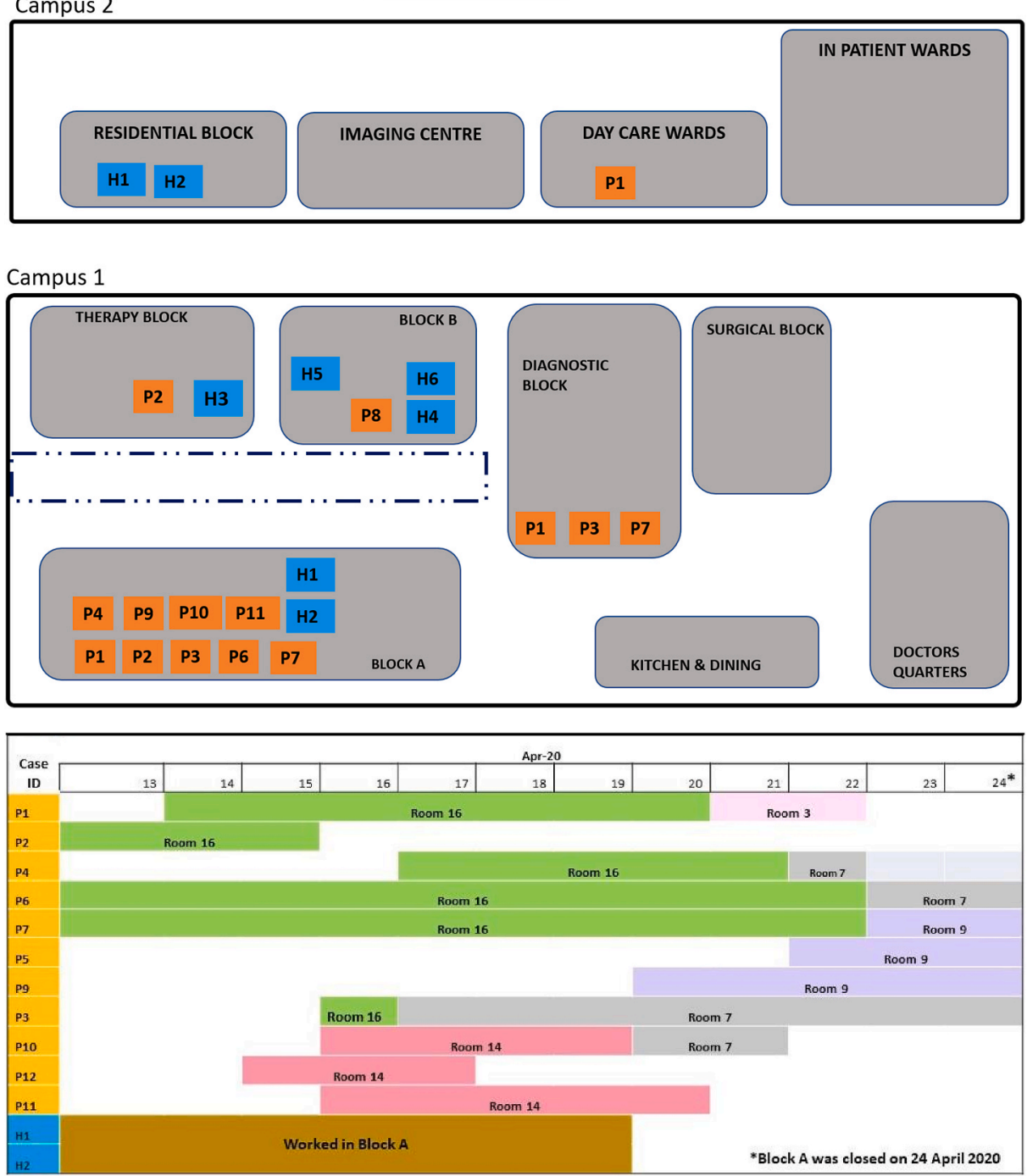

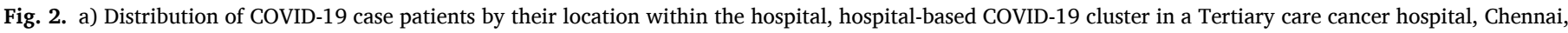

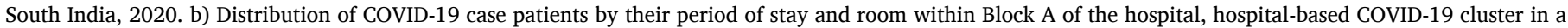
Tertiary care cancer hospital, Chennai, South India, 2020.

being hypertensive and having travelled inside India were associated with COVID-19.

Our investigations suggest that the index case-patient contracted the infection from a different referral hospital prior to admission to the Tertiary-level cancer care hospital. The local government brought to the notice of the hospital team that staff, including the doctor and nurse who performed specialised cardiac procedure for P1, had indeed tested positive for COVID-19 during the reference period. From the index casepatient, the other patients stayed in the same room, and that of the health care workers attending to them could have contracted the infection. A large hospital-based outbreak investigation demonstrated that the frequency of patient movement within a hospital plays a crucial role in spreading the disease. ${ }^{16}$ Based on the current evidence, clinical and epidemiological characteristics of COVID-19 infection among cancer patients are mostly unknown in India. It is assumed that the medical management of the cancer patients could lead to immunodeficiency and make them more susceptible to COVID-19 infection like other nosocomial infection. ${ }^{17}$ This is supported by the higher attack rate among the patients in our study.

Routine care of the patients in addition to assisting special procedures could have facilitated the transmission in this setting. Procedures that are likely to generate aerosols are considered to be associated with an increased risk for transmission to health care workers. ${ }^{18,19}$ However, evidence suggests that except for endotracheal intubation, the risks for other aerosol-generating procedures in causing respiratory diseases are still limited. ${ }^{20}$ Earlier studies from Severe Acute Respiratory Syndrome (SARS) and Middle Eastern Respiratory Syndrome (MERS) also suggest that potential aerosol-generating procedures are not associated with the increased transmission but are generally considered as high-risk procedures. ${ }^{21}$ It is also concluded that a lack of evidence may be a limitation of these studies, and current evidence is substantiated by epidemiologic data available through hospital outbreaks. ${ }^{22}$ This dynamic emphasises on the need to ensure strict personal protective gear and aseptic practices. Training of health care workers in infection control practices and use of negative pressure rooms for procedures in patients is crucial to reducing transmission of SARS-CoV-2 in hospital settings.

Further, in the analytical study, patients of male gender and age more than 33 years were identified as risk factors for COVID-19. Several biological and behavioural factors among males, such as higher angiotensin-converting enzyme-2 expression, higher levels of smoking and alcohol consumption, and frequent movements, and sometimes irresponsible attitude ${ }^{23}$ may be responsible for this higher risk. Further increased risk of COVID-19 due to comorbidities like diabetes and hypertension is well-established elsewhere as well. ${ }^{24}$ 
Table 4

Factors associated with COVID-19, Case-control study, hospital-based COVID-19 cluster in a Tertiary care cancer hospital, Chennai, South India, 2020.

\begin{tabular}{|c|c|c|c|c|c|c|}
\hline \multirow[t]{3}{*}{ Factors } & \multicolumn{4}{|c|}{ Frequency of exposures } & \multirow{3}{*}{\multicolumn{2}{|c|}{$\begin{array}{c}\text { Odds ratio }(95 \% \\
\text { CI) }\end{array}$}} \\
\hline & \multicolumn{2}{|c|}{$\begin{array}{l}\text { Cases (n } \\
=18)\end{array}$} & \multicolumn{2}{|c|}{$\begin{array}{l}\text { Controls } \\
(\mathrm{n}=113) \\
\end{array}$} & & \\
\hline & No. & $\%$ & No. & $\%$ & & \\
\hline Age $>33$ years & 11 & 61 & 53 & 47 & $1 \cdot 8$ & $\begin{array}{l}(0.6 \text { to } \\
4 \cdot 9)\end{array}$ \\
\hline Male gender & 9 & 50 & 46 & 41 & $1 \cdot 5$ & $\begin{array}{l}(0 \cdot 5 \text { to } \\
3 \cdot 9)\end{array}$ \\
\hline Had a History of travel in India & 2 & 11 & 1 & 1 & 14 & $\begin{array}{l}(1 \cdot 2 \text { to } \\
163 \cdot 0)\end{array}$ \\
\hline Being a patient & 11 & 59 & 24 & 21 & $5 \cdot 8$ & $\begin{array}{l}(2 \cdot 1 \text { to } \\
16 \cdot 6)\end{array}$ \\
\hline $\begin{array}{l}\text { Had household member with } \\
\text { COVID-19 }\end{array}$ & 2 & 12 & 7 & 6 & $1 \cdot 9$ & $\begin{array}{l}(0.4 \text { to } \\
9.9)\end{array}$ \\
\hline $\begin{array}{l}\text { Been in a closed environment with } \\
\text { COVID-19 individual }\end{array}$ & 0 & 0 & 3 & 0 & & Undefined \\
\hline $\begin{array}{l}\text { Presence of at least one } \\
\text { comorbidity }\end{array}$ & 6 & 33 & 14 & 12 & $2 \cdot 6$ & $\begin{array}{l}(0.9 \text { to } \\
7 \cdot 9)\end{array}$ \\
\hline Patients with Hypertension & 4 & 22 & 7 & 6 & $4 \cdot 3$ & $\begin{array}{l}(1 \cdot 1 \text { to } \\
16 \cdot 7)\end{array}$ \\
\hline Patients with Diabetes Mellitus & 4 & 22 & 8 & 7 & $3 \cdot 8$ & $\begin{array}{l}(1 \cdot 0 \text { to } \\
14 \cdot 1)\end{array}$ \\
\hline
\end{tabular}

Table 5

Association of being a patient and COVID-19 stratified by age and gender, Casecontrol study, hospital-based COVID-19 cluster in a Tertiary care cancer hospital, Chennai, South India, 2020.

\begin{tabular}{|c|c|c|c|c|c|c|}
\hline \multirow{3}{*}{ Strata } & \multicolumn{4}{|c|}{ Being a patient } & \multicolumn{2}{|c|}{ Odds ratio $(95 \% \mathrm{CI})$} \\
\hline & \multicolumn{2}{|c|}{$\begin{array}{c}\text { Cases }(\mathrm{n}= \\
11)\end{array}$} & \multicolumn{2}{|c|}{$\begin{array}{c}\text { Controls }(\mathrm{n}= \\
24)\end{array}$} & & \\
\hline & No. & $\%$ & No. & $\%$ & & \\
\hline \multicolumn{7}{|l|}{ Aged } \\
\hline$\leq 33$ years & 1 & 14 & 11 & 18 & 0.7 & $(0.1$ to $6 \cdot 8)$ \\
\hline$>33$ years & 10 & 91 & 13 & 25 & $30 \cdot 7$ & (3.6 to 264.0$)$ \\
\hline \multicolumn{7}{|l|}{ Gender } \\
\hline Male & 7 & 78 & 15 & 33 & $7 \cdot 2$ & $(1 \cdot 3$ to $39 \cdot 1)$ \\
\hline Female & 4 & 44 & 9 & 13 & $5 \cdot 2$ & (1.2 to $22 \cdot 9)$ \\
\hline \multicolumn{7}{|l|}{ Hypertension } \\
\hline Present & 4 & 100 & 2 & 29 & Undefined & \\
\hline Absent & 7 & 50 & 22 & 21 & 3.8 & $(1 \cdot 2$ to $12 \cdot 0)$ \\
\hline \multicolumn{7}{|l|}{$\begin{array}{l}\text { Diabetes } \\
\text { mellitus }\end{array}$} \\
\hline Present & 7 & 50 & 21 & 20 & Undefined & \\
\hline Absent & 4 & 100 & 3 & 38 & 4 & $(1 \cdot 2$ to $12 \cdot 7)$ \\
\hline
\end{tabular}

\subsection{Bias and limitations}

Our study had a few limitations. Firstly, we could suffer from selection bias on account of our inability to test all the contacts. This bias could have led to over-estimation of positivity and, therefore, the higher probability of inclusion in the study. However, we do not anticipate any influence of the same on estimated associations since exposure ascertainment was not influenced by the status of testing. Secondly, we encountered higher non-response among controls than cases. However, cases and controls were similar with respect to age and gender. Therefore, non-response is unlikely to influence magnitude of associations. Thirdly, information bias could have led to misclassification of exposures as interviewers were not masked about case status. To minimise the bias, we maximised the objective measurement of exposure factors.

\subsection{Conclusions and recommendations}

Based on the investigation of COVID-19 cluster in a super-speciality hospital, we concluded that due to favourable transmission pathways between patients and hospital staff, COVID-19 risk was higher for being
Table 6

Use of Personal Protective Equipments (PPEs) among healthcare workers, Casecontrol study, hospital-based COVID-19 cluster in a Tertiary care cancer hospital, Chennai, South India, 2020.

\begin{tabular}{|c|c|c|c|c|c|c|}
\hline \multirow{2}{*}{$\begin{array}{l}\text { Reported usage of } \\
\text { specific PPEs }\end{array}$} & \multicolumn{2}{|c|}{ Cases } & \multicolumn{2}{|c|}{ Controls } & \multicolumn{2}{|c|}{ Odds ratio $(95 \% \mathrm{CI})$} \\
\hline & No. & Total & No. & Total & & \\
\hline $\begin{array}{l}\text { Not washing hands } \\
\text { before or after } \\
\text { procedure }\end{array}$ & 1 & 2 & 2 & 21 & $9 \cdot 5$ & $\begin{array}{l}(0.4 \text { to } \\
218 \cdot 0)\end{array}$ \\
\hline $\begin{array}{l}\text { Not removing and } \\
\text { replacing PPE as per } \\
\text { protocol }\end{array}$ & 1 & 2 & 3 & 26 & $7 \cdot 6$ & $\begin{array}{l}(0.4 \text { to } \\
157 \cdot 0)\end{array}$ \\
\hline Not using mask & 1 & 3 & 2 & 28 & $6 \cdot 5$ & $\begin{array}{l}(0.4 \text { to } \\
106 \cdot 0)\end{array}$ \\
\hline Not using gloves & 1 & 3 & 4 & 26 & $2 \cdot 8$ & $\begin{array}{l}(0 \cdot 2 \text { to } \\
38 \cdot 0)\end{array}$ \\
\hline $\begin{array}{l}\text { Not washing hands } \\
\text { before or after } \\
\text { touching patient }\end{array}$ & 0 & 1 & 1 & 26 & 0 & \\
\hline $\begin{array}{l}\text { Not using disposable } \\
\text { gowns }\end{array}$ & 0 & 1 & 1 & 6 & 0 & \\
\hline Not using head cover & 1 & 1 & 1 & 7 & Undefined & \\
\hline Not using shoe cover & 0 & 0 & 1 & 7 & Undefined & \\
\hline $\begin{array}{l}\text { Not using protective } \\
\text { glasses }\end{array}$ & 1 & 1 & 1 & 6 & Undefined & \\
\hline
\end{tabular}

a patient and those having co-morbidity. Based on potential risk of spread among the hospital community in such situations, we recommended identification and disinfection of the movement pathways of the COVID-19 positive cases within the hospital, tracing of all the patients who were admitted in the hospital during the period of exposure but discharged before initiation of testing for COVID-19 and screening for Influenza-Like Illness (ILI) at the first point of contact among patients and health care workers and isolate those with ILI until confirmed for COVID-19. As a long-term measure, we recommended screening all the patients for diabetes and hypertension, mandatory usage of personal protective equipment and imposing strict infection control practices to ensure the prevention of future clusters of COVID-19 in the hospital setting. The hospital implemented these recommendations and retrained the staff to adhere to the recommendations.

\section{Contributors}

SB, NJ, MK, SC, MoK, MP, ST, VV and PG designed the study, contributed to data collection and data analysis. CPGK coordinated the specimen collection, processing and testing, contributed to the interpretation of data and writing of the manuscript. SB, NJ, MK, SC, MoK, MP, ST, SKM accessed, verified, and interpreted the data, wrote the first draft of the manuscript and revisions. JM, MS, UK, VV and AJV contributed to the investigation methods, supervision, review and editing of the manuscript. All authors approved the final version of the manuscript.

\section{Data sharing}

The anonymised individual participant data collected during the study, is available upon request to the corresponding author, after approval of a proposal with a signed data access agreement.

\section{Declaration of competing interest}

All authors have completed the ICMJE uniform disclosure form at www.icmje.org/coi_disclosure.pdf and declare no competing interests.

\section{Acknowledgement}

We thank the leadership, heads of the departments and staff of Cancer Institute (WIA), Chennai. We sincerely thank the public health 
staff and officials from the Greater Chennai Corporation for the support. We acknowledge the State Public Health Laboratory for their testing support. We thank Dr.Tarun Bhatnagar of the ICMR School of Public Health at ICMR-NIE for his inputs to the data analysis and discussion section.

\section{References}

1 Kwok KO, Chan HHH, Huang Y, et al. Inferring super-spreading from transmission clusters of COVID-19 in Hong Kong, Japan, and Singapore. J Hosp Infect. 2020;105 (4):682-685.

$2 \mathrm{Xu} \mathrm{X-K,} \mathrm{Liu} \mathrm{X-F,} \mathrm{Wu} \mathrm{Y,} \mathrm{et} \mathrm{al.} \mathrm{Reconstruction} \mathrm{of} \mathrm{transmission} \mathrm{pairs} \mathrm{for} \mathrm{novel}$ coronavirus disease 2019 (COVID-19) in mainland China: estimation of superspreading events, serial interval, and hazard of infection. Clin Infect Dis Off Publ Infect Dis Soc Am. 2020;71(12):3163-3167. https://doi.org/10.1093/cid/ciaa790.

$3 \mathrm{Lu} \mathrm{J}, \mathrm{Gu}$ J, Li K, et al. COVID-19 outbreak associated with air conditioning in restaurant, Guangzhou, China. Emerg Infect Diseases J - CDC. 2020;26(7) [cited 2020 Dec 13]; Available from: https://wwwnc.cdc.gov/eid/article/26/7/20-0764_article.

4 Mizumoto K, Kagaya K, Zarebski A, Chowell G. Estimating the asymptomatic proportion of coronavirus disease 2019 (COVID-19) cases on board the Diamond Princess cruise ship, Yokohama, Japan, 2020. Euro Surveill Bull Eur Sur Mal Transm Eur Commun Dis Bull. 2020;25(10).

5 Moriarty LF. Public health responses to COVID-19 outbreaks on cruise ships worldwide. MMWR Morb Mortal Wkly Rep. 2020;69 [cited 2020 Dec 13]. Available from: https://www.cdc.gov/mmwr/volumes/69/wr/mm6912e3.htm.

6 Atrubin D, Wiese M, Bohinc B. An outbreak of COVID-19 associated with a recreational hockey game - Florida, june 2020. MMWR Morb Mortal Wkly Rep. 2020; 69(41):1492-1493.

7 Hamner L, Dubbel P, Capron I, et al. High SARS-CoV-2 attack rate following exposure at a choir practice - skagit county, Washington, march 2020. MMWR Morb Mortal Wkly Rep. 2020;69(19):606-610.

8 Trivedi S. Coronavirus | the Story of India's Largest COVID-19 Cluster; 2020. The Hindu [Internet]. 2020 Apr 11 [cited 2020 Dec 13]; Available from: https://www.thehindu. $\mathrm{com} /$ news/national/coronavirus-nizamuddin-tablighi-jamaat-markaz-the-story-of-in dias-largest-covid-19-cluster/article31313698.ece.

9 Jahan N, Rubeshkumar P, Karuppiah M, et al. Entry and Initial Spread of COVID-19 in India: Epidemiological Analysis of Media Surveillance Data, India; 2020. Clin Epidemiol Glob Health [Internet]. 2020 Nov 7 [cited 2020 Dec 13]; Available from: http:// www.sciencedirect.com/science/article/pii/S2213398420302281.

10 Chatterjee P, Anand T, Singh KJ, et al. Healthcare workers \& SARS-CoV-2 infection in India: a case-control investigation in the time of COVID-19. Indian J Med Res. 2020; 151(5):459.

11 Private Hospital Shut in Lucknow, KGMU Staff Quarantined after Man Tests Positive for COVID-19- the New Indian Express; 2020 [cited 2020 Dec 13]. Available from: htt ps://www.newindianexpress.com/nation/2020/apr/14/private-hospital-shut-in-lu cknow-kgmu-staff-quarantined-after-man-tests-positive-for-covid-19-2130087.html.

12 Hansen S, Stamm-Balderjahn S, Zuschneid I, et al. Closure of medical departments during nosocomial outbreaks: data from a systematic analysis of the literature. $J$ Hosp Infect. 2007:65(4):348-353.

13 Covid-19, Delhi News: 2nd Delhi Hospital Babu Jagjivan Ram Memorial Sealed in 24 Hours after Staff Infected with COVID-19 [Internet]; 2020 [cited 2020 Dec 13]. Available from: https://www.ndtv.com/delhi-news/coronavirus-2nd-delhi-hospitalbabu-jagjivan-ram-memorial-sealed-in-24-hours-after-staff-infected-wi-2218545.

14 COVID-19 Early Epidemiologic and Clinical Investigations for Public Health Response; 2020 [cited 2020 Dec 20]. Available from: https://www.who.int/publications/m /item/covid-19-early-epidemiologic-and-clinical-investigations-for-public-health -response.

15 List of Operational (Initiated Independent Testing) Laboratories Approved by ICMR; 2020 [cited 2020 Dec 13]. Available from: https://www.icmr.gov.in/pdf/covid/labs/CO VID Testing Labs 12122020.pdf.

16 Lessells DR, Moosa Y, de Oliveira T. Report into a Nosocomial Outbreak of Coronavirus Disease 2019 (COVID-19) at Netcare St. Augustine's Hospital; 2020. Netcare St. Augustine's Hospital; 2020 May pp. 1-30. Available from https://www.krisp.org. za/news.php?id=421 (pdf.

17 Cornejo-Juárez P, Vilar-Compte D, García-Horton A, López-Velázquez M, ÑamendysSilva S, Volkow-Fernández P. Hospital-acquired infections at an oncological intensive care cancer unit: differences between solid and hematological cancer patients. BMC Infect Dis. 2016;10(16):274.

18 Howard BE. High-risk aerosol-generating procedures in COVID-19: respiratory protective equipment considerations. Otolaryngol Head Neck Surg. 2020;163(1): 98-103.

19 Mick P, Murphy R. Aerosol-generating otolaryngology procedures and the need for enhanced PPE during the COVID-19 pandemic: a literature review. J Otolaryngol Head Neck Surg. 2020;49(1):29.

20 Pasnick S, Carlos WG, Dela Cruz CS, Gross JE, Garrison G, Jamil S. SARS-CoV-2 transmission and the risk of aerosol generating procedures. Am J Respir Crit Care Med. 2020;202(4):13-14. https://doi.org/10.1164/rccm.2024p13. https://www.atsjo urnals.org/doi/abs/10.1164/rccm.2020C11, 2020.

21 Tran K, Cimon K, Severn M, Pessoa-Silva CL, Conly J. Aerosol generating procedures and risk of transmission of acute respiratory infections to healthcare workers: a systematic review. PLoS One. 2012;7(4), e35797.

22 Harding H, Broom A, Broom J. Aerosol-generating procedures and infective risk to healthcare workers from SARS-CoV-2: the limits of the evidence. J Hosp Infect. 2020; 105(4):717-725.

23 Bwire GM. Coronavirus: why men are more vulnerable to covid-19 than women? Sn Compr Clin Med. 2020:1-3.

24 de Almeida-Pititto B, Dualib PM, Zajdenverg L, et al. Severity and mortality of COVID 19 in patients with diabetes, hypertension and cardiovascular disease: a metaanalysis. Diabetol Metab Syndrome. 2020;12(1):75. 